Exp. Anim. 56(2), 79-84, 2007

\title{
Pharmacokinetic Interactions of Flunixin Meglumine and Enrofloxacin in ICR Mice
}

\author{
Tomoe $\mathrm{OGINO}^{1)}$ and Toshiro ARAI ${ }^{2)}$
}

\begin{abstract}
1)National Veterinary Assay Laboratory, 1-15-1 Tokura, Kokubunji, Tokyo 185-8511, and 2)Department of Veterinary Science, School of Veterinary Medicine, Nippon Veterinary and Life Science University, 1-7-1 Kyonancho, Musashino, Tokyo 180-8602, Japan
\end{abstract}

\begin{abstract}
We examined the pharmacokinetic interactions of enrofloxacin and flunixin in male ICR mice that were subcutaneously (SC) administered with both or either one of the drugs. The experiments were performed on the following three groups: flunixin alone (2 $\mathrm{mg} / \mathrm{kg}, \mathrm{SC}$ ), combination of flunixin (2 $\mathrm{mg} / \mathrm{kg}, \mathrm{SC}$ ) and enrofloxacin (10 mg/kg, SC), and enrofloxacin alone (10 mg/kg, SC). Blood samples were collected at 5, 15 and $30 \mathrm{~min}$, and $1,2,3,4,5$ and $6 \mathrm{~h}$ after the drug administration, and the pharmacokinetic parameters of flunixin and enrofloxacin were evaluated from the plasma drug concentrations. Significant changes were detected in the pharmacokinetics of flunixin following its coadministration with enrofloxacin. Coadministration of flunixin and enrofloxacin resulted in a $41 \%$ increase of the area under the curve (AUC) and a 53\% extension of the terminal half-life of flunixin; moreover, flunixin attained the maximum plasma drug concentration 2.75 times faster than when administered alone. The terminal rate constant and the maximum plasma drug concentration showed significant decreases of $34 \%$ and $33 \%$, respectively, following the coadministration of enrofloxacin and flunixin as compared to those following the administration of flunixin alone. In contrast, no significant difference in the pharmacokinetics of enrofloxacin was detected following its coadministration with flunixin, as compared to those following the administration of enrofloxacin alone. Following the administration of enrofloxacin alone or its coadministration with flunixin, the plasma level of ciprofloxacin, the metabolite of enrofloxacin, was very low or undetectable. In conclusion, the pharmacokinetics of flunixin in ICR mice are altered by the coadministration of flunixin and enrofloxacin.
\end{abstract}

Key words: enrofloxacin, flunixin meglumine, mice, pharmacokinetic interactions

\section{Introduction}

Nonsteroidal anti-inflammatory drugs (NSAIDs) function by inhibiting cyclooxygenase in the arachi- donic acid cascade. NSAIDs are widely used because of their strong analgesic and antipyretic effects. Flunixin meglumine is an NSAID that is prescribed in veterinary clinics to treat inflammation and pain.

(Received 18 July 2006 / Accepted 18 October 2006)

Address corresponding: T. Ogino, National Veterinary Assay Laboratory, 1-15-1 Tokura, Kokubunji, Tokyo 185-8511, Japan 


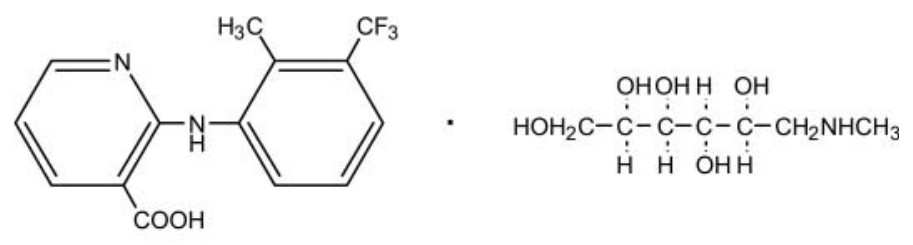

flunixin meglumine<smiles>CN1CCN(c2cc3c(cc2F)C(=O)C(C(=O)O)CN3C2CC2)CC1</smiles>

enrofloxacin<smiles>O=C(O)C1CN(C2CC2)c2cc(N3CCNCC3)c(F)cc2C1=O</smiles>

ciprofloxacin ( a metabolite of enrofloxacin )

Fig. 1. Structure of flunixin meglumine, enrofloxacin and ciprofloxacin.

Fluoroquinolone antimicrobials inhibit DNA synthesis and show bactericidal activity against gram-negative aerobes, gram-positive bacteria, and mycoplasmas. Enrofloxacin is a fluoroquinolone that is specifically marketed for use in veterinary medicine to treat respiratory and urinary tract infections $[4,9,13-15]$.

NSAIDs and antimicrobials are frequently coadministered to improve clinical signs. However, it has been reported that the distribution and elimination of antimicrobials are altered when they are coadministered with NSAIDs [3, 16]. Further, in a previous paper, we reported that coadministration of flunixin and enrofloxacin in dogs resulted in the delayed elimination of these drugs [8].

The purpose of this study was to further investigate the pharmacokinetic interactions between flunixin meglumine and enrofloxacin in male ICR mice.

\section{Materials and Methods}

\section{Animals}

Male ICR mice (5 to 6-weeks-old, body weight 25$30 \mathrm{~g})$ that were purchased from Saitama Experimental Animals Supply (Sugito, Japan) were used in the experiment. We used ICR mice in the present study because they are widely used in scientific studies. All the mice were in good health throughout the experiments, and all the experiments were conducted in accordance with the National Veterinary Assay Laboratory Guide for the Care and Use of Experimental Animals.

\section{Experimental design}

The experiments were performed as follows: in Experiment 1 , mice were administered with flunixin alone 
( $2 \mathrm{mg} / \mathrm{kg}$, subcutaneously (SC)); in Experiment 2, mice were coadministered with flunixin $(2 \mathrm{mg} / \mathrm{kg}, \mathrm{SC})$ and enrofloxacin $(10 \mathrm{mg} / \mathrm{kg}, \mathrm{SC})$; and in Experiment 3, mice were administered with enrofloxacin alone $(10 \mathrm{mg} / \mathrm{kg}$, SC). The dosage of enrofloxacin was determined by reference to a study that was reported previously [2], and $10 \mathrm{mg} / \mathrm{kg}$ was chosen as twice the dosage that was approved for dogs in that study. The drug solution was adjusted to the same volume with distilled water following single administration and coadministration, and the solution was injected at the same site in each experiments. Blood samples were collected from the inferior vena cava under anesthesia with diethyl ether. Samples were collected at 5, 15 and $30 \mathrm{~min}$, and 1, 2, $3,4,5$ and $6 \mathrm{~h}$ after drug administration. The blood samples were collected from six mice at each time point. Plasma was isolated by centrifugation at $2000 \times \mathrm{g}$ for $10 \mathrm{~min}$ and stored at $-80^{\circ} \mathrm{C}$ until assay.

\section{Analytic methods}

Flunixin concentrations in plasma were determined by high performance liquid chromatography (HPLC) as described in a previous report [8]. Plasma samples were extracted with potassium phosphate buffer $(0.3$ $\mathrm{mmol} / \mathrm{l} ; \mathrm{pH}, 3.5)$ and diethyl ether. The system consisted of a pump (880-PU, Jasco Corp, Tokyo, Japan), an automated sampler (L-7250, Hitachi Ltd, Tokyo, Japan), a column oven (CO-965, Jasco Corp, Tokyo, Japan), an ultraviolet detector (875-UV, Jasco Corp, Tokyo, Japan), and an integrator (C-R6A chromatopac, Shimadzu Corp, Kyoto, Japan). Standard curves had correlation coefficients of $>0.999$ (between concentrations of 0.05 and $10 \mu \mathrm{g} / \mathrm{ml}$ ). The intra-assay and inter-assay coefficients of variation were $1.0 \%$ and $1.6 \%$, respectively.

The concentrations of enrofloxacin and its metabolite ciprofloxacin in plasma were also assayed by reverse-phase HPLC/UV (the above-mentioned system) detection as previously described [8]. Plasma drug extraction was performed by chloroform. The standard curve for enrofloxacin was linear between concentrations of 0.05 and $10 \mu \mathrm{g} / \mathrm{ml}$ (correlation coefficient, >0.999). The standard curve for ciprofloxacin had correlation coefficients of $>0.999$ (between concentrations of 0.01 and $1 \mu \mathrm{g} / \mathrm{ml}$ ). The intra-and inter-assay coefficients of variation for enrofloxacin were $1.1 \%$ and $1.4 \%$, respectively, and for ciprofloxacin they were $0.3 \%$ and $1.5 \%$, respectively.

\section{Pharmacokinetics analysis}

The pharmacokinetic parameters were determined using a computer software program (WinNonlin 4.1, Pharsight, California, USA.). Calculations were performed using non-compartmental methods. In brief, $\mathrm{C}_{\max }$ was the highest plasma concentration, and $\mathrm{T}_{\max }$ was the earliest time at which $\mathrm{C}_{\max }$ occurred. The terminal rate constant $\left(\lambda_{\mathrm{Z}}\right)$ was obtained from the slope of the regression line at least three data points. The terminal half life $\left(\mathrm{t}_{1 / 2\left(\lambda_{z}\right)}\right)$ was $0.693 / \lambda_{\mathrm{Z}}$. Area under the curve (AUC) was calculated by using trapezoidal methods.

\section{Statistical analysis}

The comparisons of pharmacokinetic parameters between single administrations and coadministrations of flunixin and enrofloxacin were performed by using the Wilcoxon rank-sum test. A value of $P<0.05$ was considered significant.

\section{Results}

\section{Pharmacokinetics of flunixin meglumine}

The mean plasma flunixin concentrations were determined following flunixin administration alone or after its coadministration with enrofloxacin (Fig. 2). During the period from 5 to $15 \mathrm{~min}$, the mean plasma flunixin concentrations after the administration of flunixin alone were higher than those after its coadministration with enrofloxacin. Further, the plasma flunixin concentrations during the period from $30 \mathrm{~min}$ to $6 \mathrm{~h}$ after the administration of flunixin alone were lower than those

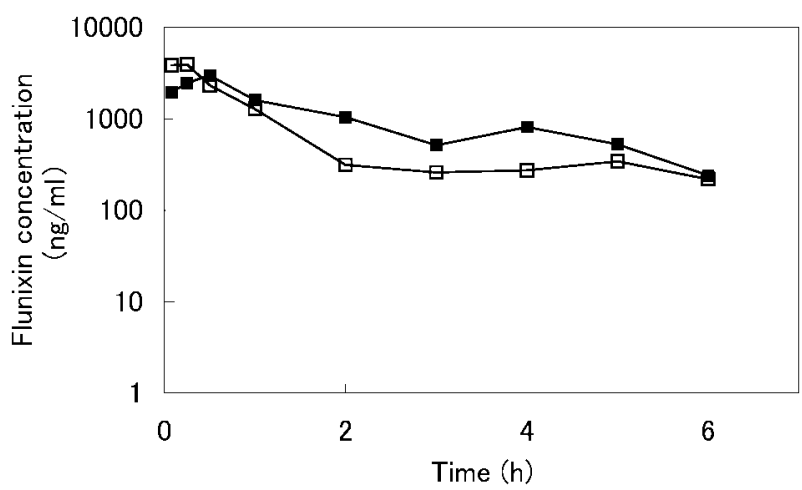

Fig. 2. Mean plasma flunixin concentrations in mice after flunixin $(2 \mathrm{mg} / \mathrm{kg}, \mathrm{SC})$ administration alone (open squares) or flunixin coadministration (closed squares) with enrofloxacin $(10 \mathrm{mg} / \mathrm{kg}, \mathrm{SC})$. 
Table 1. Pharmacokinetic parameters of flunixin following simultaneous SC injections of enrofloxacin and flunixin meglumine in mice

\begin{tabular}{lccccc}
\hline $\begin{array}{l}\text { Parameters } \\
\text { Units }\end{array}$ & $\begin{array}{c}\lambda_{\mathrm{z}} \\
\mathrm{h}^{-1}\end{array}$ & $\begin{array}{c}\mathrm{t}_{1 / 2(\lambda z)} \\
\mathrm{h}\end{array}$ & $\begin{array}{c}\mathrm{AUC} \\
\mathrm{ng} \cdot \mathrm{h} / \mathrm{ml}\end{array}$ & $\begin{array}{c}\mathrm{T}_{\max } \\
\mathrm{h}\end{array}$ & $\begin{array}{c}\mathrm{C}_{\max } \\
\mathrm{ng} / \mathrm{ml}\end{array}$ \\
\hline $\begin{array}{l}\text { Flunixin alone } \\
\begin{array}{l}\text { Mean } \\
\text { Flunixin and enrofloxacin }\end{array}\end{array}$ & 0.73 & $0.95^{*}$ & 4741.95 & 0.16 & 4553.39 \\
Mean & $0.48 \dagger$ & $1.45^{* \dagger}$ & $6666.55 \dagger$ & $0.44 \dagger$ & $3045.76 \dagger$ \\
\hline
\end{tabular}

*Harmonic mean. $†$ Significantly $(P<0.05)$ different from flunixin administration alone. $\lambda_{\mathrm{z}}$, terminal rate constant; $\mathrm{t}_{1 / 2(\lambda z)}$, terminal half life; AUC, area under the curve; $\mathrm{T}_{\max }$, time to reach maximum plasma concentration; $\mathrm{C}_{\max }$, maximum plasma drug concentration.

after its coadministration with enrofloxacin. The equation parameters derived from the pharmacokinetic constants of flunixin following the administration of flunixin alone or its coadministration with enrofloxacin were determined (Table 1). Significant changes were detected in the pharmacokinetics of flunixin following its coadministration with enrofloxacin. The coadministration of the two drugs resulted in a $41 \%$ increase of the AUC and a 53\% extension of the $t_{1 / 2(\lambda z)}$ for flunixin; $\mathrm{T}_{\max }$ for flunixin was 2.75 -fold higher than that after the administration of flunixin alone. Accordingly, after coadministration of the two drugs, $\lambda_{z}$ and $\mathrm{C}_{\max }$ for flunixin decreased by $34 \%$ and $33 \%$, respectively, as compared to that after the administration of flunixin alone.

\section{Pharmacokinetics of enrofloxacin}

The mean plasma enrofloxacin concentrations following the administration of enrofloxacin alone or its coadministration with flunixin were determined (Fig. 3). Until $2 \mathrm{~h}$ after drug administration, the plasma enrofloxacin concentrations after the administration of enrofloxacin alone were slightly lower than those after its coadministration with flunixin. In the 3 to $6 \mathrm{~h}$ period, the plasma enrofloxacin concentrations following the administration of enrofloxacin alone or its coadministration with flunixin were observed to be almost similar. The pharmacokinetic parameters of enrofloxacin following its independent administration or its coadministration with flunixin were determined (Table 2). No significant differences in the pharmacokinetic parameters of enrofloxacin were observed following its coadministration with flunixin.

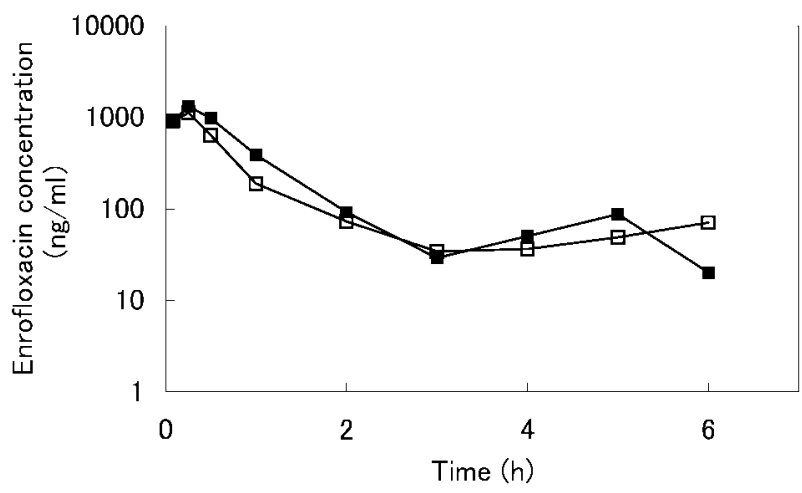

Fig. 3. Mean plasma enrofloxacin concentrations in mice after enrofloxacin $(10 \mathrm{mg} / \mathrm{kg}, \mathrm{SC})$ administration alone (open squares) or enrofloxacin coadministration (closed squares) with flunixin $(2 \mathrm{mg} / \mathrm{kg}, \mathrm{SC})$.

\section{Plasma ciprofloxacin concentrations}

The level of ciprofloxacin, the metabolite of enrofloxacin, was very low or undetectable in mice plasma following enrofloxacin administration or its coadministration with flunixin.

\section{Discussion}

We examined the pharmacokinetics of enrofloxacin and flunixin in mice that were SC administered with both or either one of the drugs. Plasma drug concentrations were determined by HPLC.

In the initial period of the experiment, from 5 to 15 min after drug administration, the mean plasma flunixin concentrations after the administration of flunixin alone were higher than those after its coadministration with 
Table 2. Pharmacokinetic parameters of enrofloxacin following simultaneous SC injections of enrofloxacin and flunixin meglumine in mice

\begin{tabular}{lccccc}
\hline $\begin{array}{l}\text { Parameters } \\
\text { Units }\end{array}$ & $\begin{array}{c}\lambda_{\mathrm{z}} \\
\mathrm{h}^{-1}\end{array}$ & $\begin{array}{c}\mathrm{t}_{1 / 2(\lambda \mathrm{z})} \\
\mathrm{h}\end{array}$ & $\begin{array}{c}\mathrm{AUC} \\
\mathrm{ng} \cdot \mathrm{h} / \mathrm{ml}\end{array}$ & $\begin{array}{c}\mathrm{T}_{\max } \\
\mathrm{h}\end{array}$ & $\begin{array}{c}\mathrm{C}_{\max } \\
\mathrm{ng} / \mathrm{ml}\end{array}$ \\
\hline $\begin{array}{l}\text { Enrofloxacin alone } \\
\text { Mean }\end{array}$ & 0.86 & $0.81^{*}$ & 1063.09 & 0.29 & 1154.95 \\
$\begin{array}{l}\text { Enrofloxacin and flunixin } \\
\text { Mean }\end{array}$ & 0.88 & $0.79 *$ & 1360.49 & 0.36 & 1330.60 \\
\hline
\end{tabular}

Abbreviations: same as for Table 1.

enrofloxacin. However, in the later period, from 30 min to $6 \mathrm{~h}$ following its coadministration with enrofloxacin, flunixin concentrations were higher than those after its independent administration. The concentrations versus time profiles of flunixin depicted an extension in $\mathrm{T}_{\max }$ and a decrease $\mathrm{C}_{\max }$ following its coadministration with enrofloxacin. It is considered that the extension of $\mathrm{T}_{\max }$ for flunixin was due to the inhibition of flunixin absorption following coadministration of enrofloxacin. There is a possibility that a mixed solution of enrofloxacin and flunixin may affect the absorption site, although, no specific change was observed in any mice. However, our previous study on dogs indicated that the mean plasma flunixin concentrations after its coadministration with enrofloxacin were always higher than those after its independent administration [8]. Similar to the study on dogs, $\lambda_{Z}$ for flunixin decreased, and $t_{1 / 2(\lambda z)}$ for flunixin increased in mice. This finding indicates that the coadministration of flunixin and enrofloxacin results in a delayed elimination of flunixin.

The plasma enrofloxacin concentrations in mice after the administration of enrofloxacin alone were similar to those after its coadministration with flunixin. Further, no significant differences were detected in the pharmacokinetics of enrofloxacin following its coadministration with flunixin. In contrast, our previous study on dogs indicated that the coadministration of flunixin and enrofloxacin induces a delayed elimination of enrofloxacin [8]. The differences in the pharmacokinetics of the drugs between dogs and mice suggest that drug elimination patterns differ among species.

It has been reported that enrofloxacin is deethylated to ciprofloxacin in many animal species $[1,5,6,11]$. However, in this study, ciprofloxacin could not be detected in mice plasma following the administration of enrofloxacin alone or its coadministration with flunixin. Similarly, other studies on pigs have reported that ciprofloxacin could not be detected in the plasma after the intramuscular and intravenous injection of enrofloxacin [12].

Taken together these results show that coadministration of flunixin and enrofloxacin resulted in a delayed elimination of flunixin in both dogs and mice. On the other hand, enrofloxacin pharmacokinetics did not differ after its coadministration with flunixin in mice, whereas this coadministration with flunixin induced a delayed elimination of enrofloxacin in dogs.

A possible explanation for this species-dependent flunixin and enrofloxacin interaction in mice is that there exist differences in the metabolism and elimination patterns of enrofloxacin between species. For instance, significant variation in the metabolism of enrofloxacin has been observed in many animal species. Further, it has been reported that enrofloxacin is metabolized to ciprofloxacin in many animals $[1,5,6$, 11]; however, in the present study ciprofloxacin was not detected in mice plasma after enrofloxacin administration. In addition, it has been reported that the elimination of enrofloxacin in mice was fastest among five animal species [2]. This rapid elimination of enrofloxacin in mice is consistent with the results obtained in this study.

Studies using human and rat hepatic microsomes have reported that fluoroquinolones inhibit cytochrome $\mathrm{P}$ 450 1A (CYP1A) and cytochrome P-450 3A (CYP3A) activities [7]. It has also been reported that fluoroquinolones inhibit the CYP1A activity in the hepatic microsome in dogs [10]. However, to our knowledge, few studies have reported that enzyme inhibition is related to enrofloxacin in mice. Therefore, it is important to identify the drug metabolism enzyme 
related to enrofloxacin by an in vitro study. In vitro studies on mice microsomes may clarify the speciesdependent flunixin and enrofloxacin interaction.

In conclusion, it is clear that the pharmacokinetics of flunixin in mice are altered by its coadministration with enrofloxacin. This result is similar to that obtained in dogs. However, species differences in the pharmacokinetic interactions of flunixin and enrofloxacin are apparent between dogs and mice. In future studies we will research the differences in drug metabolism, including enzyme induction and enzyme inhibition. Future studies should aim to clarify the mechanism of the pharmacokinetic interactions between flunixin and enrofloxacin in mice.

\section{References}

1. Anadon, A., Martinez-Larranaga, M.R., Diaz, M.J., Bringas, P., Martinez, M.A., and Fernandez-Cruz, M.L. 1995. Pharmacokinetics and residues of enrofloxacin in chickens. Am. J. Vet. Res. 56: 501-506.

2. Bregante, M.A., Saez, P., Aramayona, J.J., Fraile, L., Garcia, M.A., and Solans, C. 1999. Comparative pharmacokinetics of enrofloxacin in mice, rats, rabbits, sheep, and cows. Am. J. Vet. Res. 60: 1111-1116.

3. EL-Banna, H.A. 1999. Pharmacokinetic interactions between flunixin and sulphadimidine in horses. Dtsch. tierarztl. Wschr. 106: 400-403.

4. Hannan, P.C.T., Windsor, G.D., de Jong, A., Schmeer, N., and Stegemann, M. 1997. Comparative susceptibilities of various animal-pathogenic mycoplasmas to fluoroquinolones. Antimicrob. Agents Chemother. 41: 20372040.

5. Kaartinen, L., Salonen, M., Alli, L., and Pyorala, S. 1995. Pharmacokinetics of enrofloxacin after single intravenous, intramuscular and subcutaneous injections in lactating cows. J. Vet. Pharmacol. Therap. 18: 357-362.

6. Kung, K., Riond, J.L., and Wanner, M. 1993. Pharmacokinetics of enrofloxacin and its metabolite ciprofloxacin after intravenous and oral administration of enrofloxacin in dogs. J. Vet. Pharmacol. Therap. 16: 462 468.

7. McLellan, R.A., Drobitch, R.K., Monshouwer, M., and Renton, K.W. 1996. Fluoroquinolone antibiotic inhibit cytochrome P450-mediated microsomal drug metabolism in rat and human. Drug Metab. Dispos. 24: 1134-1138.

8. Ogino, T., Mizuno, Y., Ogata, T., and Takahashi, Y. 2005. Pharmacokinetics interactions of flunixin and enrofloxacin in dogs. Am. J. Vet. Res. 66: 1209-1213.

9. Prescott, J.F. and Yielding, K.M. 1990. In vitro susceptibility of selected veterinary bacterial pathogens to ciprofloxacin and norfloxacin. Can. J. Vet. Res. 54: 195197.

10. Regmi, N.L., Abd El-Aty, A.M., Kuroha, M., Nakamura, M., and Shimoda, M. 2005. Inhibitory effect of several fluoroquinolones on hepatic microsomal cytochrome P-450 1 A activities in dogs. J. Vet. Pharmacol. Therap. 28: 553557.

11. Richez, P., Monlouis, J.D., Dellac, B., and Daube, G. 1997. Validation of a therapeutic regimen for enrofloxacin in cats on the basis of pharmacokinetic data.J. Vet. Pharmacol Therap. 20 (Suppl 1): 152-153.

12. Richez, P., Pedersen Morner, A., de Jong, A., and Monlouis, J.D. 1997. Plasma pharmacokinetics of parentally administered danofloxacin and enrofloxacin in pigs. J. Vet. Pharmacol. Therap. 20 (Suppl 1): 41-42.

13. Tasker, S., Helps, C.R., Day, M.J., Harbour, D.A., Gruffydd-Jones, T.J., and Lappin, M.R. 2004. Use of a Taqman PCR to determine the response of Mycoplasma haemofelis infection to antibiotic treatment. J. Microbiol. Methods 56: 63-71.

14. Vancutsem, P.M., Babish, J.G., and Schwark, W.S. 1990. The fluoroquinolone antimicrobials: structure, antimicrobial activity, pharmacokinetics, clinical use in domestic animals and toxicity. Cornell. Vet. 80: 173-186.

15. Walker, R.D., Stein, G.E., Hauptman, J.G., and MacDonald, K.H. 1992. Pharmacokinetic evaluation of enrofloxacin administered orally to healthy dogs. Am. J. Vet. Res. 53: 2315-2319.

16. Whittem, T., Firth, E.C., Hodge, H., and Turner, K. 1996. Pharmacokinetic interaction between repeated dose phenylbutazone and gentamicin in the horse. J. Vet. Pharmacol. Therap. 19: 454-459. 